\title{
TipsheETS FOR TEACHING GraduATE AtTRIBUTES IN AN ONLINE ENVIRONMENT: FACULTY SUPPORT THAT IS ACCessible, Current, Relevant, AND Tangible
}

\author{
Anita M. Parker, Nicole Dyck, Jason P. Carey \\ Faculty of Engineering, University of Alberta, Edmonton, Alberta \\ aparker@ualberta.ca,jpcarey@ualberta.ca
}

\begin{abstract}
Evidence-based teaching strategies (EBTs) are connected to positive outcomes for students. Engineering instructors are tasked with using EBTs to scaffold studentmasteryof graduate attributes, nowamidst an upsurge in online, remote course delivery. The Graduate Attribute Tipsheet Series developed by the Faculty of Engineering at the University of Alberta provides instructors with current, relevant, and tangible information in a succinct format that is mindful of their high workloads and time constraints. The tipsheet less-ismore development process was careful and iterative to ensure only the most important, useful points from high quality, credible sources were included. Lessons learned from this initiative can be applied to future resources that support instructors in their use of EBTs in an online learning context and are responsive to the inevitable flux of teaching circumstances in engineering education.
\end{abstract}

Keywords: Evidence-based teaching, graduate attributes, engineering education, online learning, faculty support

\section{INTRODUCTION}

Implementation of evidence-based teaching strategies (EBTs), such as active learning and formative assessment, by instructors in higher education can positively impact student learning and achievement.[1,2,3] Despite this, passive, lecture-style teaching methods prevail in the physical and virtual classroom. $[1,4,5]$ Suggested reasons for this discrepancy are varied, including instructor workloads and availability of resources.[4] Perceived support is one factor of an instructor's willingness and motivation to implement EBTs, which can come in the form of succinct, targeted resources, mindful that teaching is just one component of an instructor's responsibilities.[1,4]

A fast-tracked move to online, remote course delivery as a result of the COVID-19 pandemic that began in early 2020 necessitated an overhaul of existing resources for instructors across the University of Alberta to now incorporate the effective use of educational technology.
Since 2009, instructors in the Faculty of Engineering have been reshaping theircourses to integrate graduate attributes and satisfy accreditation requirements.[6] The Graduate Attribute Tipsheet Series was a resource (of digital, printable PDFs) created at the faculty level in 2019 originally intended to provide concise, concrete guidance for instructors in this regard. The tipsheets were written with the assumption of in-class learning. Over the summer of 2020, the tipsheets were reconstructed to align with the pandemic-driven online teaching and learning circumstances, with care taken to maintain the succinct, and therefore accessible, nature of the resource.

Creation of the revised Graduate Attribute Tipsheet Series (2020 version) was guided by the question, "What is the most current, relevant, and tangible information required by engineering instructors to use evidence-based strategies for teaching graduate attributes in an online, remote learning context, such that each tipsheet does not surpass a two-page maximum?" The purpose of this paper is to share the development process of the tipsheet series, now tailored to the teaching and learning of specific professional skill-based graduate attributes in a virtual environment. This initiative models the gathering of documentation about EBTs to create a resource that is useful to instructors and responsive to a time of changing circumstances in engineering education.

\subsection{Review of the Literature}

The "evidence" behind evidence-based teaching strategies includes positive outcomes such as increased student engagement and grades.[1,2] EBTs are connected to the learning theory of constructivism wherein knowledge is actively created by the student through meaningful experiences and reflection.[7] Constructivist activities and assessments are student-centered and have real-world relevance as students build necessary knowledge and skills for their discipline of study. [8] This is in contrast to a passive, uninterrupted lecture approach that is commonplace in higher education.[1] 
EBTs are necessary for student mastery of the skillbased component of graduate attributes, which were introduced as a program accreditation requirement by the Canadian Engineering Accreditation Board (CEAB) in 2009.[6] Graduate attributes are grounded in outcomesbased education, a concept now found across higher education disciplines. $[9,10]$ The intention of this pedagogical shift from inputs (what is taught) to outputs (what is learned) has been to prepare students for their participation in the global engineering community.[6,9]

Instructor workload has been significantly impacted by the introduction of graduate attributes since 2009 , and now amidst an upsurge in online, remote course delivery.[4,11,12,13] This extra time and effort by instructors manifests as professional development for learning about EBTs and the innovative use of educational technology in relation to graduate attributes, and subsequently to prepare and teach courses that have integrated these aspects. $[1,2,14]$ Instructor willingness to invest energy into EBTs and effective online learning strategies is influenced in part by the availability of support, such as succinct, targeted resources that are mindful of constraints on their time. [1, 3, 4, 15]

\section{METHODOLOGY}

The original and revised versions of the Graduate Attribute Tipsheet Series were created with the writing process of Flower and Hayes (1977) in mind.[16] The following stages refer to the revised version creation specifically.

Stage one: Planning and gathering. The intended user of the tipsheets was determined to be an engineering instructor who: (1) is balancing the demands of teaching, research, and service (i.e., has a high workload); (2) is interested in implementing EBTs and can benefit from concrete ideas; (3) is responsible for scaffolding and measuring student mastery of graduate attributes; (4) is beholden to an online, remote course delivery context. Keywords were garnered from this profile of the intended user and used to search academic databases and Google for sources, such as book chapters, journal articles, conference proceedings, blogs, and other informal media such as infographics and videos. It was decided to focus on one online teaching strategy and one digital tool per tipsheet, as outlined in Table 1.

Stage two: Generating content. From the large collection of sources gathered in stage one, information was evaluated for its relevancy and then extracted and arranged in an unpolished and nonlinear manner. Since the boundaries of each graduate attribute, online teaching strategy, and digital tool are indistinct, all tipsheets were considered as a whole to ensure consistency and avoid redundancies. Analogously, this was the building of chain links but not yet assembling the chain.
Stage three: Refining. The rough, disjointed components created in stage two were edited, amalgamated, and formatted into their final versions. Any wordiness was eliminated, and headings and subheadings were carefully written to precisely represent what was included in each section. Visual layout considerations included the positioning of each component to maximize use of space on the two pages of each tipsheet while not compromising readability. See Appendix A for the final version of one tipsheet.

Table 1: Teaching strategies and tools selected for each graduate attribute tipsheet.

\begin{tabular}{|l|l|l|}
\hline $\begin{array}{c}\text { Graduate } \\
\text { Attribute / } \\
\text { Tipsheet }\end{array}$ & \multicolumn{1}{|c|}{$\begin{array}{c}\text { Online Teaching } \\
\text { Strategy }\end{array}$} & \multicolumn{1}{|c|}{$\begin{array}{c}\text { Online Digital } \\
\text { Tool }\end{array}$} \\
\hline Problem analysis & $\begin{array}{l}\text { Collaborative } \\
\text { brainstorming }\end{array}$ & Digital whiteboard \\
\hline Team work & $\begin{array}{l}\text { Collaborative } \\
\text { content creation }\end{array}$ & Wikis \\
\hline Communication & $\begin{array}{l}\text { Asynchronous oral } \\
\text { presentations }\end{array}$ & $\begin{array}{l}\text { Video pre- } \\
\text { recordings }\end{array}$ \\
\hline Professionalism & Shared reading & Social annotation \\
\hline Ethics and equity & Case instruction & Discussion forum \\
\hline Life-long learning & Reflection & ePorfolios \\
\hline
\end{tabular}

\section{FINDINGS}

Direct evidence (such as number of downloads) and indirect evidence (such as user feedback via surveys) on the tipsheets series has not yet been obtained due to pandemic-related prioritization of tasks within the Faculty of Engineering. Findings at the moment are limited to lessons learned over the three stages of the tipsheet series development process.

Some lessons learned in stage one (planning and gathering) were as follows:

- The web-based sharing of knowledge and ideas by educators globally is limitless. For most topics, engineering-specific (or other STEM) resources are available.

- Querying academic databases or mainstream Google is a winding and lengthy path that takes time to unfold. It is important to keep a record of search histories on given topics so as not to go around in circles.

- Over the course of the search process, quality, credible resources begin to stand out from their mediocre counterparts. Time spent finding these final 
destinations translates into time saved for the tipsheet user.

Some lessons learned in stage two (generating content) were as follows:

- Taking a less-is-more approach requires keeping the tipsheet user in mind by asking, "If I was teaching this on Monday morning, what would I need to know?" Anything nice-to-know is extraneous and can be omitted.

- The most important material naturally presents itself through repetition in multiple sources.

- Embedded links to external destinations can transform the tipsheet into a portal; however, integrate them sparingly so as to avoid the tipsheet simply being an entry point into the vastness of the internet.

Some lessons learned in stage three (refining) were as follows:

- Building all the tipsheets simultaneously and iteratively helps to achieve consistency in layout, writing tone and style, and depth of details.

- Printable PDFs are a wise format, because they are engageable online and predictable when printed. The tipsheet content is suitable for other forms, such as a website, infographic, or video, which is something to consider for a future initiative.

- Basic word processing software is adequate for creating a well-formatted, aesthetically pleasing document that is easily updated. High production services are not required.

\section{DISCUSSION}

Engineering instructors balance the demands of teaching, research, and service under normal circumstances. As part of a teaching faculty, they have full course loads, as well as additional duties, such as working with PhD students who themselves are building their portfolios. Steep learning curves and tight deadlines, as driven by the pandemic, heightened the priority of teaching responsibilities in 2020 and now into 2021. With this in mind, the Graduate Attribute Tipsheet Series was revised to align with online, remote course preparation and delivery.

Several of the graduate attributes outlined by the CEAB target professional (i.e., nontechnical) skills. Their nebulous and subjective nature makes them challenging to teach and assess.[6] For this reason, the attributes chosen for the tipsheet series were: Problem analysis, Team work, Communication, Professionalism, Ethics and equity, and Life-long learning. The most beneficial starting point for practical information about the teaching of graduate attributes was Felder and Brent (2016) Teaching and learning stem: A practical guide.[17] Other sources were used to fill in the gaps and provide the most up-to-date information about educational technology.

Care was taken to ensure that each tipsheet included only the most current and relevant information and provided tangible, Monday-morning-ready ideas for teaching graduate attributes online. Each tipsheet emphasizes that professional skill development is a result of cycles of practice and reflection, which is facilitated by targeted tasks and instructor feedback.[17] External links lead to specific activity ideas and rubrics. The overall premises (program and career relevance), EBTs, and digital tools highlighted in the tipsheets are summarized as follows.

Problem analysis: Traditional lectures and homework to solve well-structured problems does not prepare engineering students for the complex, ill-structured problems of the workplace.[17] Instead, students benefit when they are engaged in all steps of the problem-solving process, namely: (1) define; (2) explore; (3) plan; (4) implement; and (5) reflect. Activities that encourage creative thinking are brainstorming, troubleshooting, and formulating problems, rather than solving pre-fabricated ones. Online, collaborative brainstorming and organizing of ideas can be achieved using a digital whiteboard application. In this shared virtual space, students can meet in real-time or contribute to a discussion asynchronously on their own time.

Team work: The complex nature of engineering problems makes them highly unsolvable by individuals. Team work is the norm in engineering, yet employers continue to point out the deficiency of this professional skill in the workplace.[17] Sub-skills include communication, leadership, decision making, time management, and conflict resolution. Student resistance to group work can be mitigated by stressing its pedagogical and career-related benefits. Cooperative learning can be achieved online with a wiki tool. In this shared virtual space, students can generate ideas, strategize solutions, and co-create knowledge.

Communication: Written and oral communication is foundational to all the professional skills of an engineer.[17] While some programs have standalone communication courses, integrating this content into technical courses throughout an engineering undergraduate program is recommended. Low-stakes writing and speaking tasks can be integrated into everyday classroom activities or homework and can help students prepare for high stakes reports and oral presentations. Oral presentations can occur in real-time with web conferencing and asynchronously by means of pre-recorded videos, such as narrated slide presentations or screen capture.

Professionalism: Engineers deal with laws and regulations on an ongoing basis when, for example, creating safe workplaces, negotiating contracts, obtaining permits, navigating intellectual property, and more.[18] Learning legislation and policy is challenging and can be 
enhanced by active learning opportunities, such as illustrative cases, role play, and shared reading and annotation. Online shared reading can be achieved with a social annotation tool, which facilitates discussion and peer interaction, even in large classes and by students who may not otherwise participate.

Ethics and equity: Ethical awareness and behaviour is central to the everyday professional lives and conduct of engineers; therefore, students require opportunities to recognize and make decisions around ethical issues.[19] While programs often delegate engineering ethics to a standalone course, another approach is to integrate ethics activities into many courses across a program. The use of case studies can encompass issues such as conflict of interest, welfare of society, whistle blowing, and property issues such as patents and innovations. Cases can be discussed in real-time with web conferencing and asynchronously by means of a discussion forum within a learning management system.

Life-long learning: Practicing engineers are required to set professional development goals and provide evidence of achievement on an ongoing basis. [17] In preparation for their future careers, engineering students need to develop a capacity for self-directed lifelong learning. This includes the ability to: determine learning needs and goals; assemble resources and implement strategies; and reflect upon outcomes. A reflection task is a structured opportunity for students to consider a single problem, a larger project, an entire course, or even their academic program. Specific reflection task activities are journals, self-assessments, exam wrappers, and ePortfolios. In engineering education, ePortfolios provide evidence of student learning and attainment of graduate attributes that is not always possible with traditional assessment methods. Students take personal responsibility for their efforts and accomplishments, which resembles what they can anticipate in a future recruitment process.

Overall, development of the Graduate Attribute Tipsheet Series was rooted in following three considerations. First, discipline-specific expertise may suffice for a traditional "tell them and test them " approach, but instructors require encouragement and resources to bring active, authentic learning activities and as sessments and innovative use of educational technologies into their courses.[14] Second, while support usually targets new instructors in their building of foundational teaching skills, it can also be tailored for experienced instructors in their efforts to stay on the leading edge of teaching excellence.[20] Finally, the brevity of the tipsheet format is intentional, because instructors have large workloads and little free time, requiring all supports to be readily accessible and easily consumed.[3, 15]

\section{CONCLUSION}

Evidence-based teaching encompasses the use of instructional methods that are supported by empirical evidence of positive outcomes for students.[1,23] Engineering instructors are continually growing professionally; however, they are in a time of pandemicdriven transformation of teaching, for which they require support.[1,4] The Graduate Attribute Tipsheet Series developed within the Faculty of Engineering at the University of Alberta provides instructors with current, relevant, and tangible information about using EBTs to teach graduate attributes in an online, remote learning context. The two-page maximum of each tipsheet addresses circumstances of the heavy workload and time constraints that instructors face at the moment.

The development process for the tipsheet was iterative through stages of planning and gathering, content generation, and refining, which was necessary to extract the most important points from high quality, credible sources, to maintain consistency, and to avoid redundancies. The chosen PDF format for the tipsheets enables users to view online or print a paper copy. However, the resource would lend itself to other formats, such as blog entries, infographics, and videos. Lessons learned from the development process can be applied to future resource initiatives that make EBTs available to engineering instructors and are responsive to the inevitable flux of circumstances in engineering education.

\section{Acknowledgements}

The authors would like to acknowledge the Faculty of Engineering at the University of Alberta for their support of the Graduate Attribute Tipsheet Series initiative.

\section{References}

[1] M. E. Bathgate, O. R. Aragón, A. J. Cavanagh, J. K. Waterhouse, J. Frederick and M. J. Graham, "Perceived supports and evidence-based teaching in college STEM," International Journal of STEM Education, vol. 6, no. 11, p. 14pp, 2019.

[2] J. E. Groccia and W. Buskist, "Need for evidencebased teaching," New Directions for Teaching and Learning, vol. 128, pp. 5-11, 2011.

[3] C. Harrington, Ensuring learning: Supporting faculty to improve student success, London: Rowan \& Littlefield Publishers, 2020.

[4] N. Nelson and R. Brennan, "A snapshot of engineering education in Canada," in Proceedings of the Canadian Engineering Education Association (CEEA) Conference, June 3-6, Vancouver, 2018. 
[5] E. Nordmann, C. Horlin, J. Hutchison, J.-A. Murray, L. Robson, M. K. Seery and J. R. D. MacKay, "Ten simple rules for supporting a temporary online pivot in higher education," PLoS Computational Biology, vol. 16, no. 10, p.e1008242, 2020.

[6] A. M. Parker, E. Watson, M. Ivey and J. P. Carey, "Approaches to graduate attributes and continual improvement processes in faculties of engineering across Canada: A narrative review of the literature," in Proceedings of the Canadian Engineering Education Association (CEEA) Conference June 812, Ottawa, 2019.

[7] S. O. Bada, "Constructivism learning theory: A paradigm for teaching and learning," Journal of Research \& Method in Education, vol. 5, no. 6, pp. 66-70, 2015.

[8] K. Sambell, L. McDowell and C. Montgomery, Assessment for learning in higher education, Abington, Oxon: Routledge, 2013.

[9] D. Owens, "Outcome-based education and engineering accreditation," in CAST Innovation and Integration Engineering Education Accreditation International Symposium, April 11, Beijing, 2016.

[10] W. G. Spady, Outcome-based education: Critical issues and answers, Arlington, Virginia: American Association of School Administrators, 1994.

[11] B. D. Espinoza and M. Neal, "Incorporating contextual knowledge in faculty professional development for online teaching," Journal on Centers for Teaching and Learning, vol. 10, pp. 2444, 2018.

[12] M. Kebritchi, A. Lipschuetz and L. Santiague, "Issues and challenges for teaching successful online courses in higher education: A literature review," Journal of Educational Technology Systems, vol. 46, no. 1, pp. 4-29, 2017.
[13] W. L. Worley and L. S. Tesdell, "Instructor time and effort in online and face-to-face teaching: Lessons learned," IEEE Transactions on Professional Communication, vol. 52, no. 2, pp. 138-151, 2009.

[14] M. Cleveland-Innes and S. Gauvreau, "Faculty role change: Adjustments to the influence of online teaching and learning," European Journal of Open, Distance and eLearning, EDEN Special Issue, pp. 134-144, 2015.

[15] V. Diaz, P. B. Garrett, E. R. Kinley, J. F. Moore, C. M. Schwartz and P. Kohrman, "Faculty development for the 21 st century," Educause Review, vol. 44, no. 3, pp. 46-55, 2009.

[16] L. S. Flower and J. R. Hayes, "Problem-solving strategies and the writing process," College Teaching, vol. 39, no. 4, pp. 449-461, 1977.

[17] R. M. Felder and R. Brent, Teaching and learning STEM: A practical guide, San Fransico, California: Jossey-Bass, 2016.

[18] G. Soo, M. Kumaraswamy, S. T. Ng and F. Y. Y. Ying, "Role-playing for group learning of law in engineering and construction programs," Journal of Legal Affairs and Dispute Resolution in Engineering and Construction, vol. 1, no. 4, pp. 169-172, 2009.

[19] C. B. Fleddermann, Engineering Ethics, 4th ed., Upper Saddle River, NJ: Prentice Hall Education Inc., 2012.

[20] T. Green, J. Alejandro and A. H. Brown, "The retention of experienced faculty in online distance education programs: Understanding factors that impact their involvement," International Review of Research in Open and Distance Learning, vol. 10, no. 3, p. 16pp, 2009. 


\subsubsection{Problem analysis An ability to use} appropriate knowledge and skills to identify, formulate, analyze, and solve complex engineering problems in order to reach substantiated conclusions.

(Engineers Canada, 2018)
Traditional use of lectures and homework to solve well-structured problems doesn't prepare engineering students for the complex, ill-structured problems of the workplace. Instead, students benefit when instructors repeatedly and consistently model a step-by-step problem-solving process, providing practice and feedback for ALL the steps (not just implementation).
Tough problems are multifaceted and require collaboration and creativity. Some creative thinking exercises are:

- Brainstorming or brainwriting possible solutions. Focus on quantity, withhold criticism, welcome unusual ideas. Brainwriting can help avoid verbal traffic jams and encourage participation.

- Troubleshooting to explain unexpected results. This can be done in a small group discussion, or can be incorporated into an assignment or test question. Frame unexpected results as opportunities for improved understanding, and possibly for major scientific breakthroughs.

- Formulating problems. Rather than solving prefabricated problems, students tap into high-level creative thinking skills when they devise and solve problems themselves. Use of samples and a rubric can help students understand the elements of a well-constructed problem.

\section{Helpful Links}

- Hands-on activities for innovative problem solving Describes team-based activities that enhance creative thinking.

- Encouraging divergent thinking These two articles provide classroom-ready ideas for students to build their problem solving and creative thinking skills.

- Problem Solving VALUE Rubric Designed to measure the quality of the problem-solving PROCESS (not end product).
Step 1: Define Determine the known and unknown details, as well as the constraints and criteria of the problem. Perhaps create a visual representation, such as a diagram or flow chart.

Step 2: Explore Expert problem solvers routinely use important attributes to classify problems and identify solutions from that classification. Identify and collect the necessary background knowledge and information.

Step 3: Plan From a brainstormed list of possible solutions, choose the best one in the context of constraints and criteria. Define tasks and necessary resources.

Step 4: Implement Carrying out a solution plan is likely not linear and will require revisiting of previous steps. Be patient and persistent.

Step 5: Reflect This metacognitive aspect of the problem-solving process is key to transferring the skills gained to new situations. Some questions for reflection:

- Does the solution satisfy all the required deliverables? Does it meet the criteria and constraints?

- Do all the calculations make physical sense? Are the derived mathematical functions valid?

- Might a better solution exist? If so, how can I find it?

- What have I learned from this problem?

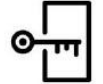

Skill development is a result of cycles of practice and reflection. Students can develop professional skills with tasks that are followed by self-reflection and instructor feedback. These tasks can be low-stakes (formative, short) or high-stakes (having an impact on course grades). 


\section{APPENDIX A: SAMPLE TIPSHEET, continued}

Teaching Problem Analysis Online $\begin{aligned} & \text { This section of each tipsheet includes one teaching } \\ & \text { strategy and one digital tool. Use the entire graduate } \\ & \text { attribute tipsheet series for a collection of online } \\ & \text { teaching ideas and resources. }\end{aligned}$

\section{Strategy: Online Brainstorming}

Brainstorming is a group discussion technique for generating a large quantity of non-redundant ideas. It is well-suited for engineering problems that characteristically are complex and have multiple possible solutions. Brainstorming activities boost students' skills for creativity and innovation, which will follow them beyond their university studies. Rules of a brainstorming session encourage the combining and modification of ideas and completely disallow criticisms among peers; any and all ideas are welcome.

When done online in real time or asynchronously, brainstorming sessions can accommodate larger groups, cultivate ideas of greater number and depth, reduce social anxiety, and increase engagement by students who might not otherwise participate.

\section{Helpful Links}

- Brainstorming exercises in an undergraduate engineering course (article with specific teaching strategies and lessons learned)

- Teaching creativity in engineering (article about brainstorming and other activities to foster the creative process)

- How to use Google Jamboard for remote teaching (video tutorial, 12:27)

\section{Tool: Digital Whiteboard}

A digital whiteboard is a web-based application that provides students who are geographically dispersed with a shared virtual space to brainstorm and organize ideas. Students can meet synchronously in real-time or contribute to the discussion asynchronously on their own time. The whiteboard allows for free-hand contributions, such as drawing and posting sticky notes, resulting in a page that may resemble a mind map or pinboard. The digital whiteboard tool provides anonymity, parallel communication, and automatic record keeping.

Google Jamboard is a digital whiteboard application that is completely free of charge, and other tools (free and paid) have similar functionalities. Usually only the instructor needs to create an account and then provide students with a link and editing access.

Having several low-stakes brainstorming activities throughout an online course can help students increase their skill with the tool and confidence in contributing to the conversations. Instructors may scaffold the activities by providing clear directions, expectations of user contributions, and assessment criteria (e.g. depth, uniqueness, and relevance of contributions). They may wish to choose groups mindfully, monitor and provide feedback, and debrief as a class after each brainstorming activity. Both instructors and students may require technical support with the digital tool.

References and Further Reading

Al-Samarrie, H., \& Hurmuzan, S. (2018). A review of brainstorming techniques in higher education. Thinking Skills and Creativity, 27, 78-91. Campbell, M., Detres, M., \& Lucio, R. (2019). Can a digital whiteboard foster student engagement? Social Work Education, 38(6), 735-752. Centre for Teaching Excellence, University of Waterloo. (n.d.). Teaching problem-solving skills. Available at https://uwaterloo.ca/centre-for-teaching-excellence/teaching-resources/teaching-tips/developing-assignments/cross-discipline-skills/teac hing-problem-solving-skills

Engineers Canada. (2018). Canadian Engineering Accreditation Board: 2018 accreditation criteria and procedures. Available at https://engineerscanada.ca/sites/default/files/accreditation/Accreditation-criteria-procedures-2018.pdf

Felder, R. M. \& Brent, R. (2016). Problem-solving skills. In Teaching and learning STEM: A practical guide (pp. 189-212). San Francisco, CA: Jossey-Bass.

Jonassen, D., Strobel, J., \& Lee, C. B. (2006). Everyday problem solving in engineering: Lessons for engineering educators. Journal of Engineering Education, 95(2).

Liu, Z. E., \& Schönwetter, D. J. (2004). Teaching creativity in engineering. International Journal of Engineering Education, 20(5), 801-808.

Raviv, D. (2004). Hands-on activities for innovative problem solving. 2004 ASEE Annual Conference, June 20, 2004, Salt Lake City, Utah. https://peer.asee.org/14062

Raviv, D. (2012, June), Encouraging divergent thinking. 2012 ASEE Annual Conference \& Exposition, June 12, 2012, San Antonio, Texas. https://peer.asee.org/21283

Tebbe, P. (2005, June). Brainstorming exercises as an active learning component of thermal system courses. Proceedings of the 2005 American Society for Engineering Education Annual Conference. 